\title{
Comparative SEM Observation of Silver-Nitrate at Resin- Dentin Interface: Nanoleakage Study
}

Turki A. Bakhsh ${ }^{1 *}$, Maryam R. Al-Zayer ${ }^{2}$, Noor G. Al-Sahwan², Zainab Al-bahrani ${ }^{2}$, Ahmad S. Bakry,3, Ahmed O. Jamleh ${ }^{4}$, Ehab Z. Alsayed $^{5}$, Mona Mandurah' ${ }^{5}$, Mona Abbassy ${ }^{2}$

${ }^{1}$ Operative Dentistry Department, Faculty of Dentistry, King Abdulaziz University, Jeddah 21381, Saudi Arabia

${ }^{2}$ Faculty of Dentistry, King Abdulaziz University, Jeddah 21381, Saudi Arabia

${ }^{3}$ Faculty of Dentistry, Alexandria University, Egypt

${ }^{4}$ College of Dentistry, King Abdullah International Medical Research Center, King Saud bin Abdulaziz University for Health Sciences - National Guard Health Affairs, Saudi Arabia

${ }^{5}$ Ministry of Health, Saudi Arabia

\begin{abstract}
Background: Most of one-bottle self-etch dental adhesives or so-called "all-in-one" system contains a mixture of hydrophilic and hydrophobic components that are dissolved in an organic solvent. This variability between the adhesives would affect their interaction with tooth structures. Flaw in this interaction, represented by poor dentin hybridization might affect the treatment success. Thus, the objective of the study was to compare between two different all-in-one self-etch adhesives, by examining the nanoleakage expression at the dentin-resin interface.
\end{abstract}

Methodology: Two all-in-one self-etch adhesives; water-based Tetric-N bond adhesive (TN; Ivoclar/Vivadent) and ethanol/water-based Tri-S bond plus (TS; Kuraray Noritake) adhesive, were used for bonding resin composite to human dentin. In order to prepare the specimen for nanoleakage evaluation, all specimens were sectioned, coated with nail-varnish and subjected to ammoniacal silver nitrate solution followed by developing solution. Then, images were taken under scanning electron microscope (SEM) and investigated by energy-dispersive X-ray spectroscopy (EDS) to trace the silver grains at the dentin-resin interface.

Result: Unlike in TS group that did not show silver deposition throughout the bonded area, the TN group showed heavy silver deposition along the hybrid layer as well as throughout the adhesive layer using SEM/EDS.

Conclusion: It can be concluded that water-based all-in-one adhesive would adversely affect the longevity of polymeric dental restoration as it showed heavy silver deposition along the dentin-resin interface.

\section{Introduction}

Nanoleakage can be defined as porosities within the hybrid layer zone of dentin-resin interface in area that was not filled with polymerized resin. Dentin hybridization is challenging as the dentine surface is a heterogeneous vital substrate with a low surface energy and outward dentinal fluid flow [1]. The quality of dentin hybridization is influenced by the formula of the functional monomers [2]. The functional monomer methacryloyloxi-decyl-dihydrogen-phosphate (10-MDP) has shown great binding affinity to hydroxyapatite (Ca-P) as it was reported in the literature [2,3]. Poor dentin hybridization with incomplete monomer penetration into the demineralized or hybridized dentin zone could lead to marginal discoloration, recurrent caries, loss of the restoration, and post-operative tooth sensitivity [4]. It has shown that the acid-etch technique was successful in enamel bonding and has effectively eliminated the microleakage at the enamel-restoration interface. However, dentin hybridization is more challenging as the dentine surface is a heterogeneous vital substrate with low surface energy and outward dentinal fluid flow [1]. Incomplete monomer penetration into the demineralized dentin or poor dentin hybridization could negatively affect the bonding longevity that can be measured using dye penetration tests $[1,2]$. The degree of dye penetration depends on the deepness of the demineralized dentin as well as the ability of the adhesive system to penetrate into the dentinal tubules [4]. In addition, the interaction of these adhesives with dentin is mainly dependent on the functional monomers and the solvents [5].

Water is an essential component in one-step self-etch adhesive or so-called "all-in-one" adhesive system. The investigator F. Tay et al. showed that incomplete water removal from the hybrid layer using onestep self-etch adhesives would result in water-tree nanoleakage pattern that leads to regional suboptimal polymerization. Moreover, even upon following manufacturer instructions, nanoleakage in some self-etch adhesives still may occur even in the absence of dentin perfusion due to the variation in the adhesive formula and their bonding approach [6-8].

Correspondence to: Turki A. Bakhsh, Department of Operative Dentistry, Faculty of Dentistry, King Abdulaziz University, P.O.Box 114759, Jeddah 21381, Saudi Arabia, Tel: 966-12-6401000 ext: 20326; E-mail: taabakhsh@kau.edu.sa

Key words: adhesive, functional monomers, water-based adhesive, SEM, nanoleakage

Received: February 02, 2017; Accepted: February 15, 2017; Published: February 18,2017 
Therefore, considering the importance of different bonding strategies, composition and solvent contained in adhesive systems and the influence of these factors may have on the quality of bonding to dentin, the aim of this in-vitro study was to qualitatively compare between water-based and water/ethanol-based one-step self-etch adhesives by examining the silver nitrate uptake at dentin-resin interface. The tested hypothesis was there is no difference between water-based and water/ethanol-based all-in-one adhesives in the silver nitrate uptake.

\section{Material and methods}

The selection and usage of the ten extracted non-caries premolar teeth were carried out in this study according to the guideline approved by King Abdulaziz University ethical committees and in accordance with the Helsinki Declaration of 1975.

\section{Experimental design}

Two one-step self-etch dental adhesives; Tetric-N bond self-etch adhesive (TN; Ivoclar/Vivadent, Liechtenstein) and Tri-S bond plus adhesive (TS; Kurary Noritake, Japan) were used in this study. The composition of the restorative materials is listed in Table 1.

The teeth were stored in thymol solution for a month before use. The occlusal third of each tooth was trimmed to expose the underlying superficial dentine surface, which was later polished by 600 -grit SiC paper under running water for $1 \mathrm{~min}$ to create a standardized smear layer.

The teeth samples were divided into two experimental groups (TN,
TS). Each group ( $n=5)$ was bonded with one of the adhesives (TN, TS) and light-cured according to the manufacturer instructions. Then, Clearfil Majesty Posterior (Kurary Noritake, Japan) resin composite was placed on the occlusal surface in two layers, each within $1.5 \mathrm{~mm}$ thickness. Each composite layer was light-cured according to the manufacturer's recommendations using LED light cure $(1200 \mathrm{~mW} /$ $\mathrm{cm}^{2}$ ).

\section{Nanoleakage preparation}

To complete resin composite setting, the samples were stored in $37^{\circ} \mathrm{C}$ distilled water for $24 \mathrm{hrs}$. After that, the samples were sectioned longitudinally to approximately $2 \mathrm{~mm}$ thickness serial slabs (3 slabs/ sample) using low-speed sawing machine with water lubricant (IsoMet, Buehler, USA). The specimen slabs were polished with 1200-grit SiC paper under running water and then coated with 2 layers of fast drying nail-varnish, away from the dentin-composite interface by $1 \mathrm{~mm}$ on each side. All slabs were stored in distilled water before nanoleakage evaluation.

Ammonical silver nitrate was prepared in dark room by dissolution of $25 \mathrm{mg}$ of silver nitrate (Sigma Chemical, USA) in $25 \mathrm{ml}$ of distilled water. Then, ammonium hydroxide was added drop by drop to titrate the black solution until it became clear. The sectioned slabs with polish nail varnish were immersed in the silver nitrate solution for $24 \mathrm{hrs}$. After that, the slabs were washed with distilled water and placed in a photo-developer solution for $8 \mathrm{hrs}$ under florescent light to convert the silver/diamine silver ions into metallic silver grains [9].

The silver-stained resin-bonded specimens were trimmed by 1200 -

Table 1. Restorative materials used in this study.

\begin{tabular}{|c|c|c|c|}
\hline $\begin{array}{c}\text { Material (Manufacture) } \\
\text { Code }\end{array}$ & Ingredients & Lot no. & Direction of use \\
\hline $\begin{array}{c}\text { Tetric N- Bond } \\
\text { Self- Etch } \\
\text { (Ivoclar/Vivadent) } \\
\text { TN } \\
\text { pH: } 1.5\end{array}$ & $\begin{array}{ll}\text { - } & \text { Bis-acrylamide derivative } \\
\text { - } & \text { Bis-methacrylamide dihydrogen phosphate } \\
\text { - } & \text { hydroxyl alkyl methacrylamide } \\
\text { - } & \text { diphenyl }(2,4,6-\text { trimethylbenzoyl }) \text { phosphine oxide } \\
\text { - } & \text { Nano-fillers }\left(\mathrm{SiO}_{2}\right) \\
\text { - } & \text { Initiators } \\
\text { - } & \text { Stabilizers }\end{array}$ & S22554 & $\begin{array}{l}\text { 1- Apply a thick layer of the adhesive and brush in } \\
\text { for at least } 30 \mathrm{sec} \text {. } \\
\text { 2- Disperse excess amounts of the adhesive with } \\
\text { a strong stream of air until there is no longer any } \\
\text { movement of the material. } \\
\text { 3- Polymerize the adhesive for } 10 \mathrm{sec}(>500 \mathrm{~mW} / \\
\left.\mathrm{cm}^{2}\right) \text {. }\end{array}$ \\
\hline $\begin{array}{c}\text { Tri-S Bond Plus } \\
\text { (Kurary Noritake dental) } \\
\text { TS } \\
\text { pH: } \mathbf{2 . 3}\end{array}$ & $\begin{array}{ll}\text { - } & \text { 10-MDP } \\
\text { - } & \text { Bis-GMA } \\
\text { - } & \text { HEMA } \\
\text { - } & \text { Hydrophilic aliphatic dimethacrylate } \\
\text { - } & \text { Colloidal silica } \\
\text { - } & \text { Sodium fluoride } \\
\text { - } & \text { Photoinitiators } \\
\text { - } & \text { Accelerators } \\
\text { - } & \text { Initiators } \\
\text { - } & \text { Water }\end{array}$ & 3В0009 & $\begin{array}{l}\text { 1- Apply bond for } 10 \mathrm{sec} \text {. } \\
\text { 2- Dry with mild pressure air flow for } 5 \mathrm{sec} \text {. } \\
\text { 3- Light-cure for } 10 \mathrm{sec} \text {. }\end{array}$ \\
\hline $\begin{array}{l}\text { Clearfil Majesty Posterior } \\
\text { composite } \\
\text { restoration }\end{array}$ & $\begin{array}{ll}- & \text { Bis-GMA } \\
- & \text { TEGDMA } \\
\text { - } & \text { Silanated silica } \\
\text { - } & \text { Filler } \\
\text { - } & \text { Silanated glass ceramics } \\
\text { - } & \text { Surface treated alumina microfiller } \\
\text { - } & \text { Dimethobic aromatic } \\
\text { Others }\end{array}$ & 0122AA & Curing for $20 \mathrm{sec}$ using LED. \\
\hline
\end{tabular}

- Abbreviations: 10-MDP; 10-methacryloyloxydecyl dihydrogenphosphate, HEMA; 2- hydroxyethyl methacrylate, Bis-GMA; bisphenol A glycerolate dimethacrylate, TEGDMA triethylene glycol dimethacrylate. 
grit SiC paper under running water for 2 min then polished using diamond pastes and polishing films in a descending order $(6,3,1 \mu \mathrm{m})$ followed by ultra-sonication in a water bath for $10 \mathrm{~min}$.

\section{Ultra-structural observation}

The dentine specimens were mounted on aluminum stubs, dehydrated, coated with gold sputter and observed under the scanning electron microscopy (SEM) (JCM-6000 Plus Versatile Benchtop, Japan) equipped with energy-dispersive X-ray spectroscopy (EDS) for element analysis to detect silver deposition and the nanoleakage expression along the bonded interface. The EDS detection of the present elements $\mathrm{Ag}, \mathrm{P}, \mathrm{Ca}, \mathrm{Si}$ at the dentin-resin interface were assessed by the EDS graphs software (SEM/EDS; JEOL, Japan).

\section{Results}

Characterization of the interfacial morphology of TN and TS groups and the distribution of silver grains along the resin-dentin interface by SEM/EDS are shown in Figures 2,3. The TN group showed thick adhesive layer $(\geq 20 \mu \mathrm{m})$ infiltrated with distinct reticular silver depositions (Figure 2). In addition, heavy silver deposition along dentin-resin interface and extended into the hybrid layer were also perceived (Figure 2). In contrast, TS group showed thin adhesive layer $(\leq 10 \mu \mathrm{m})$ and the dentin-resin interface was almost diminished of silver particles as it was confirmed by SEM/EDS (Figure 3 ).

\section{Discussion}

Many studies investigated microleakage expression at the dentinresin interface; however, the nanoleakage expression might address very detailed concerns $[1,10-13]$. Nanoleakage expression is an effective method for the identification of these degradation pathways and uses silver nitrate as a nanoleakage tracer [14]. These nanoleakage tracers were successfully detected by transmission electron microscope and SEM and their existence was confirmed by EDS $[11,15,16]$.

Many report in the literature attributed the formation of blisters or voids within the adhesive or the hybrid layer to functional monomerhydroxyapatite interaction, decomposition of the adhesive monomer, poor resin tags and monomer infiltration as well as incomplete removal of the solvent/water from the adhesive layer [7,11,12,17-19].

Organic solvents are utilized in all-in-one adhesives to blind the hydrophobic and hydrophilic monomers within the adhesive

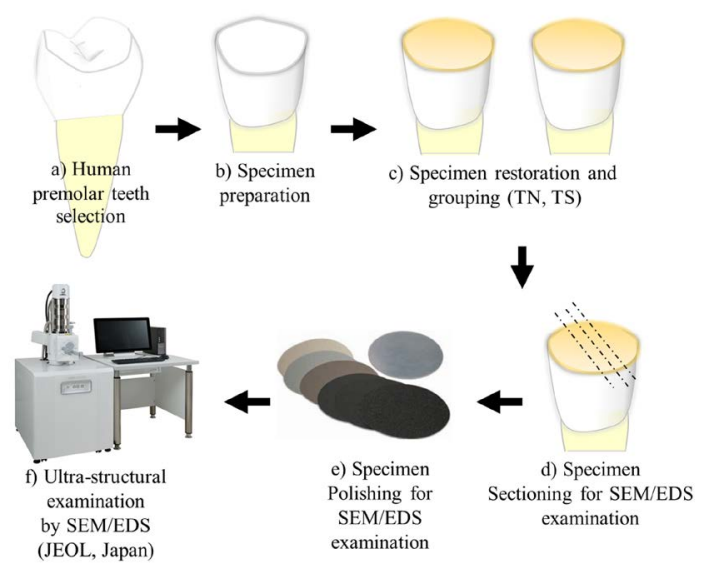

Figure 1. A drawing graph is showing the experimental design and sample preparation for nanoleakage evaluation.

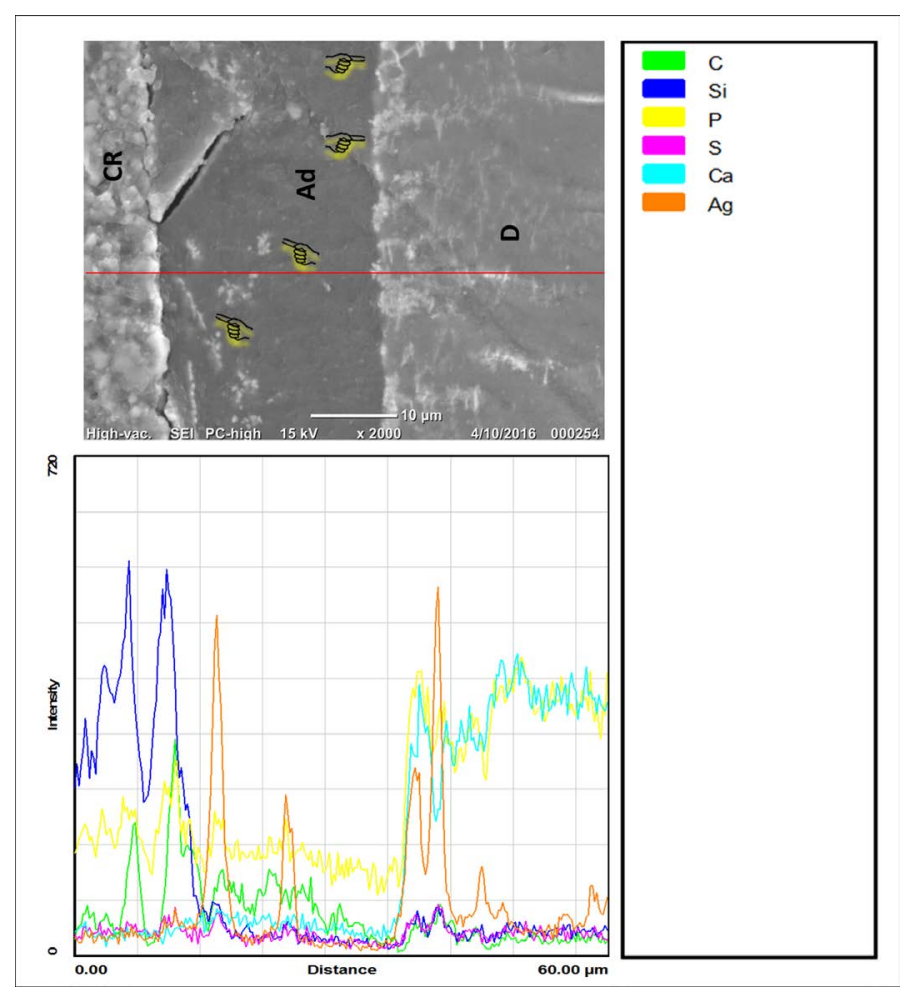

Figure 2. Graphs representing SEM/ EDS findings at resin-dentine interface after silver penetration of TN group. Apparently, traces of silver grains through resin-dentin interface in this group can be detected as indicated by the index pointers on SEM image and it was confirmed by EDS. CR, Composite resin; Ad, Adhesive; D, Dentin; Ag, Silver, Ca, Calcium; Si, Silica; C, Carbon; P, Phosphate.

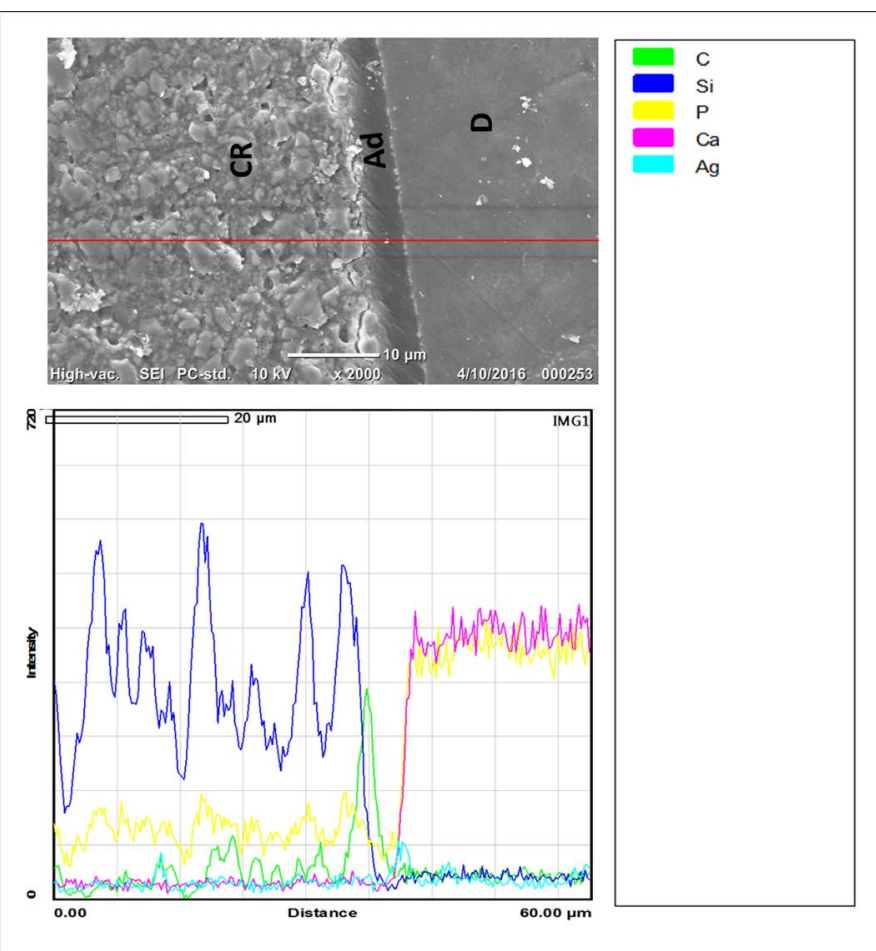

Figure 3. Graphs representing SEM/EDS results at resin-dentine interface after silver penetration of TS group. The hybrid layer in TS group presented scantydeposits of silver particles throughout resin-dentin interface in this group as it wasapparent on SEM image and they wereundetectable by EDS. CR, Composite resin; Ad, Adhesive; D, Dentin; Ag, Silver, Ca, Calcium; Si, Silica; C, Carbon; P, Phosphate. 
bottle. Some adhesive contains alcohol, acetone or water, while other adhesives contain a combination of these solvents. In some circumstances, prolonged adhesive application beyond the manufacturer recommendations or delayed adhesive curing could lead to rapid solvent evaporation, which could cause monomer-solvent phase separation $[8,20]$. Interestingly, the $\mathrm{TN}$ adhesive contains only water as solvent $(20-30 \%$ by wt), which has a low vapor pressure $(2.3$ $\mathrm{kPa}$ at $20^{\circ} \mathrm{C}$ ). This means it requires a prolong time to evaporate and possibly may not be completely removed from the adhesive in adhesive drying-step before curing [21]. Consequently, the water remnants will be incorporated within the hybrid layer as voids and act as suboptimal polymerization zones within the adhesive causing chemically assisted degradation and adhesive failure [6,21-23]. On the other hand, the solvents in TS adhesive are water and ethanol (vapor pressure; 5.95 $\mathrm{kPa}$ at $20^{\circ} \mathrm{C}$ ). It can be speculated that the ethanol contents may contributed to the rapid water removal from the adhesive and hybrid layer before curing, which positively diminished the nanoleakage from the hybrid layer and enhanced the superior outcomes of this group [21]. The poor effect was confirmed at nano-scale using silver-nitrate contrasting agent. However, combining water with ethanol would improve adhesive interaction with hard tooth structure.

The capability of 10 -MDP monomer in providing consistently stable and strong bonds to hydroxyapatite has been reported $[3,24,25]$. Unlike in TN adhesive, TS adhesive contains 10-MDP monomer that incorporates a chemical interaction with $\mathrm{Ca}-\mathrm{P}$ in dentin and promote for superior interfacial bonding as it was observed at dentin-resin interface $[2,26]$. Moreover, the lack of silver infiltration in TS adhesive could be attributed to the fluoride contents in the adhesive, which may possibly enhanced the interfacial bonding with the dentin [21,23]. For TN adhesive, our findings are coinciding with previous report on the association of water-based adhesive with poor mechanical properties and heavy interfacial silver deposition along the interface $[18,27]$. Moreover, the low $\mathrm{pH}$ value of TN adhesive (1.5) facilitated monomers infiltration deep into the dentin, however incomplete water removal had led to silver deposition at deeper level of the hybrid layer.

Lastly, the manufacturer recommended applying a thick layer of TN adhesive, followed by a strong air-drying before polymerization. However, the adhesive layer was still thicker in comparison to TS adhesive (Figure 2 and 3). The increased adhesive thickness in TN group promoted more water trapping throughout the adhesive and confirm our previous speculation. Moreover, the air-drying step in TN adhesive was not controlled by a time frame, but until no movement of the material, which is subjective and based on operators' decision.

Therefore, the tested hypothesis was rejected as the water alone has an adverse effect on the interfacial interaction between dental adhesive and tooth structure. The poor effect was confirmed at nano-scale using silver nitrate contrasting agent. However, combining water with ethanol would improve adhesive interaction with hard tooth structure.

\section{Conclusion}

It can be concluded that water-based all-in-one adhesive would adversely affect the longevity of polymeric dental restoration. The current study suggests that prolong air-drying for these water-based self-etch adhesives is recommended, however their performance in a long-term degradation process should be carefully evaluated.

\section{Acknowledgment}

This work was supported by the Deanship of Scientific Research
(DSR), King Abdulaziz University, Jeddah, under grant number (G1436-165-293). The author, therefore, acknowledges and thanks the DSR for technical and financial support. The author declares no potential conflicts of interest with respect to the authorship and/or publication of this article.

\section{References}

1. Li H, Burrow MF, Tyas MJ (2000) Nanoleakage patterns of four dentin bonding systems. Dent Mater 16: 48-56.[Crossref]

2. Yoshida Y, Nagakane K, Fukuda R, Nakayama Y, Okazaki M, et al. (2004) Comparative study on adhesive performance of functional monomers. J Dent Res 83: 454-458. [Crossref]

3. Nurrohman H, Nikaido T, Takagaki T, Sadr A, Ichinose S, et al. (2012) Apatite crystal protection against acid-attack beneath resin-dentin interface with four adhesives: TEM and crystallography evidence. Dent Mater28:89-98.[Crossref]

4. Dorfer CE, Staehle HJ, Wurst MW, Duschner H, Pioch T (2000) The nanoleakage phenomenon: influence of different dentin bonding agents, thermocycling and etching time. Eur J Oral Sci 108:346-51.[Crossref]

5. Pegado RE, do Amaral FL, Flório FM, Basting RT (2010) Effect of different bonding strategies on adhesion to deep and superficial permanent dentin. Eur J Dent 4: 110-117. [Crossref]

6. Tay FR, Pashley DH, Yoshiyama M (2002) Two modes of nanoleakage expression in single-step adhesives. J Dent Res 81: 472-476.[Crossref]

7. Chersoni S, Suppa P, Breschi L, Ferrari M, Tay FR, et al. (2004) Water movement in the hybrid layer after different dentin treatments. Dent Mater20:796-803.[Crossref]

8. Toledano M, Osorio R, Ceballos L, Fuentes MV, Fernandes CA, et al. (2003) Microtensile bond strength of several adhesive systems to different dentin depths. Am J Dent 16: 292-298.[Crossref]

9. Makishi P, Shimada Y, Sadr A, Tagami J, Sumi Y (2011) Non-destructive 3D imaging of composite restorations using optical coherence tomography: Marginal adaptation of self-etch adhesives. $J$ Dent39:316-325.[Crossref]

10. Bakhsh TA, Sadr A, Shimada Y, Tagami J, Sumi Y (2011) Non-invasive quantification of resin-dentin interfacial gaps using optical coherence tomography: validation against confocal microscopy. Dent Mater27:915-925.[Crossref]

11. Sano H, Yoshiyama M, Ebisu S, Burrow MF, Takatsu T, et al. (1995) Comparative SEM and TEM observations of nanoleakage within the hybrid layer. Oper Dent 20: 160-167.[Crossref]

12. Duarte S Jr, Phark JH, Varjao FM, Sadan A (2009)Nanoleakage, ultramorphological characteristics, and microtensile bond strengths of a new low-shrinkage composite to dentin after artificial aging. Dent Mater 25:589-600.[Crossref]

13. D'Alpino PH, de Farias NC, Silva MS, de Goes MF, Gonzalez AH, et al. (2013) Compatibility between silorane adhesive and simplified methacrylate-based adhesive systems. Dent Mater J32:263-73. [Crossref]

14. Hashimoto M, Yamaguchi S, Imazato S (2015)Nanoleakage and Durability of Resin/ Dentin Bonds. Curr Oral Health Rep2:195-201.

15. Suppa P, Breschi L, Ruggeri A, Mazzotti G, Prati C, et al. (2005) Nanoleakage within the hybrid layer: a correlative FEISEM/TEM investigation. $J$ Biomed Mater Res B ApplBiomater 73: 7-14.[Crossref]

16. Sano H, Takatsu T, Ciucchi B, Horner JA, Matthews WG, et al. (1995) Nanoleakage: leakage within the hybrid layer. Oper Dent 20: 18-25.[Crossref]

17. Tay FR, Pashley DH, Yiu CK, Sanares AM, Wei SH (2003) Factors contributing to the incompatibility between simplified-step adhesives and chemically-cured or dual-cured composites. Part I. Single-step self-etching adhesive. J Adhes Dent 5: 27-40.[Crossref]

18. Koliniotou-Koumpia E, Kouros P, Koumpia E, Helvatzoglou-Antoniades M (2014) Shear bond strength of a "solvent-free" adhesive versus contemporary adhesive systems. Braz J Oral Sci 13:64-9.

19. Van Landuyt KL, Mine A, De Munck J, Countinho E, Peumans M, et al. (2008) Technique sensitivity of water-free one-step adhesives. Dent Mater 24: 1258-1267. [Crossref]

20. Van Landuyt KL, De Munck J, Snauwaert J, Coutinho E, Poitevin A, et al. M (2005) Monomer-solvent phase separation in one-step self-etch adhesives. J Dent Res84:1838.[Crossref] 
21. Bakhsh TA, Sadr A, Shimada Y, Mandurah MM, Hariri I, et al. (2013) Concurrent evaluation of composite internal adaptation and bond strength in a class-I cavity. $J$ Dent 41: 60-70.[Crossref]

22. Bakhsh TA, Sadr A, Tagami J (2014) Focused ion beam processing for transmission electron microscopy of composite/adhesive interfaces. J Adhes Sci Technol29:232-43.

23. Bakhsh TA, Sadr A, Mandurah MM, Shimada Y, Zakaria O, et al. (2015) In situ characterization of resin-dentin interfaces using conventional vs. cryofocused ion-beam milling. Dent Mater 31: 833-844.[Crossref]

24. Yoshida Y, Yoshihara K, Nagaoka N, Hayakawa S, Torii Y, et al. (2012) Self-assembled
Nano-layering at the Adhesive interface. J Dent Res 91: 376-381.[Crossref]

25. Van Landuyt KL, Snauwaert J, De Munck J, Peumans M, Yoshida Y, et al (2007) Systematic review of the chemical composition of contemporary dental adhesives. Biomaterials 28: 3757-3785.[Crossref]

26. Nikaido T, Weerasinghe DD, Waidyasekera K, Inoue G, Foxton RM, et al. (2009) Assessment of the nanostructure of acid-base resistant zone by the application of all-inone adhesive systems: Super dentin formation. Biomed Mater Eng19:163-71.[Crossref]

27. Al-Agha EI, Alagha MI (2015) Nanoleakage of Class V Resin Restorations Using Two Nanofilled Adhesive Systems. J Int Oral Health 7: 6-11.[Crossref]

Copyright: $\mathbb{C} 2017$ Bakhsh TA. This is an open-access article distributed under the terms of the Creative Commons Attribution License, which permits unrestricted use, distribution, and reproduction in any medium, provided the original author and source are credited. 